\title{
CAV2 promotes the growth of renal cell carcinoma through the EGFR/PI3K/Akt pathway
}

This article was published in the following Dove Press journal: OncoTargets and Therapy

Fu Liu'

Zhi Shangli

Zhili $\mathrm{Hu}^{2}$

'The First People's Hospital of Ziyang, Sichuan, People's Republic of China;

${ }^{2}$ The Second Hospital Affiliated

to Chongqing Medical University,

Chongqing, People's Republic of China
Background: Caveolin-2 (CAV2) is reported to have an important role in cancer. The following study investigated the expression and function of CAV2 in kidney cancer in vitro and in vivo.

Materials and methods: Real-time PCR, immunohistochemistry and Western blotting analysis were used to determine CAV2, epidermal growth factor receptor (EGFR), phosphatidylinositol 3-kinase (PI3K) and protein kinase B (Akt) in kidney cancer cell line OS-RC-2 and clinical specimens. The role of CAV2 in maintaining kidney cancer malignant phenotype was examined by wound healing assay, Matrigel invasion assays and mouse orthotopic xenograft model.

Results: Higher expression of CAV2 was found in renal cell carcinoma tissue compared to normal tissue. Furthermore, increased expression of CAV2 was associated with cancer progression. Also, silencing of CAV2 inhibited the proliferation, migration and invasion, as well as the expression of EGFR, PI3K and p-Akt in OS-RC-2 cells in vitro, and OS-RC-2 xenograft growth in vivo.

Conclusion: Our results revealed that CAV2 promotes the growth of renal cell carcinoma through EGFR/PI3K/Akt pathway.

Keywords: Caveolin-2, CAV2, EGFR, PI3K, p-Akt, renal cell carcinoma, invasion

\section{Introduction}

Renal cell carcinoma (RCC) is the most common type of renal malignant tumor. Currently, surgery is still considered as the main treatment approach for most types of RCC; even though its efficacy remains controversial. ${ }^{1-3}$ Drug resistance is common and represents a major cause of RCC death. RCC progression is usually accompanied with uncontrollable proliferation, distant metastasis and recurrence..$^{4-7}$ However, the exact molecular mechanism of RCC is still unclear and needs to be further investigated.

Caveolin-2 (CAV2) is a member of the caveolae family which has an essential role in intracellular cell transport and signal transduction. ${ }^{8}$ Higher expression of CAV2 has been associated with different types of cancer progression including lung, prostate, renal and breast cancer. ${ }^{9-12}$ In breast tumor, CAV2 expression has been strongly associated with high histological grade ${ }^{13}$ and poor prognosis. ${ }^{14}$ Conflicting observations have been reported by Sagara et al, who found that CAV2 expression was suppressed in breast cancer tissues compared to normal tissues and that the reduced CAV1 was significantly associated with increasing tumor size. ${ }^{15}$ In addition, a positive correlation between plasma CAV2 levels and progression of prostate cancer ${ }^{16}$ and $\mathrm{RCC}^{17}$ were also observed. Nevertheless, the exact role of CAV2 in RCC remains unexplored. 
In this study, we found an abnormal expression of CAV2 in RCC tissues. In addition, we found that silencing of CAV2 inhibits tumor biological behavior in vitro and in vivo through the EGFR/PI3K/Akt pathway.

\section{Materials and methods Immunohistochemistry}

The tissue chip, including 86 cancer tissues and 10 normal tissues were purchased from US Biomax (cat no KD2085, $\mathrm{Xi}$ An, China). The flow of immunostaining was performed by the streptavidin-peroxidase method. ${ }^{18}$ The staining intensity was scored as $0,1,2$ or 3 , while percentage of stained cells was scored as $1(<25 \%), 2(26 \%-50 \%), 3(51 \%-75 \%)$, or $4(>75 \%)$. The final score was obtained by multiplying the intensity and percentage scores. The score below six scores were defined low expression. The score over six scores were defined high expression. The use of human samples was approved by the Ethics Committee of Chongqing Medical University.

\section{RT-PCR (reverse transcription- polymerase chain reaction)}

RT-PCR was done according to previously described method. ${ }^{19}$ Briefly, total RNA was isolated from cancer cells using TRIzol reagent (cat no T9424, Sigma-Aldrich Co., Aldrich, MO, USA) according to the manufacturer's protocol. All-in-One First-Strand cDNA Synthesis Kit was used to reverse transcribe the total RNA into cDNA (cat no 1708890, Bio-Rad Laboratories Inc., Hercules, CA, USA). Real-time PCR was performed with All-in-One ${ }^{\mathrm{TM}}$ qPCR mix (GeneCopoeia, Guanzhou, People's Republic of China). The following primers were used: CAV2 (cat no HQP054857) and GAPDH (cat no HQP070342) purchased from GeneCopoeia. The experiments were performed in triplicate in the same reaction, and the results of the RT-PCR experiments were analyzed using the $2^{-\Delta \Delta \mathrm{Ct}}$ method.

\section{Cell culture and reagents}

Human RCC cells OS-RC-2 were acquired from Cell bank of Chinese Academy of Sciences (TCHu 40). The cells were maintained in RPMI-1640 medium supplemented with 10\% FBS, $2 \mathrm{mM}$ L-glutamine, $100 \mathrm{U} / \mathrm{mL}$ penicillin and streptomycin in a humidified atmosphere with $5 \%$ $\mathrm{CO}_{2}$ at $37^{\circ} \mathrm{C}$. siRNA sequences were synthesized by GenePharma Co., Ltd (Shanghai, People's Republic of China). The following sequences were targeted for CAV2. CAV2-1:5'-GCAAAUACGUAAUGUACAAGU-3'; CAV22:5'-GGAGAUUGGGAUACUGUAAUA-3'; and negative control siRNA: 5'-UUCUUCGAAGGUGUCACGU-3'.

\section{CCK-8 assay}

The cellular proliferation was determined by the CCK-8 assay (cat no CK04, Japan) according to the manufacturer's instruction..$^{20,21}$

\section{Cell migration and invasion assays}

The cell migration and invasion assays were performed in accordance with our previous studies. ${ }^{22,23}$ Briefly, OS-RC-2 cells were cultured in a six-well plate until reaching $80 \%$ confluency. The medium was replaced with serum-free medium. After the wounding, the distance between two wounds was measured at 0 and 72 hours. The invasion assays were performed as follows: the upper side was coated using Matrigel basement membrane matrix for 2 hours at $37^{\circ} \mathrm{C}$. The OS-RC-2 cells were added into the top chamber, and then incubated for 48 hours; $6 \%$ paraformaldehyde was then used to fix the invasive cells. They were then stained in $0.5 \%$ crystal violet (Beyotime) and counted.

\section{Western blot}

Western blot analysis was performed as previously described. ${ }^{24}$ Three independent experiments in a certain condition were subjected to Western blot analysis. The CAV2 (ab3417), EGFR (ab52894), PI3K (ab40776), Akt (ab38449) and GAPDH (ab8245) antibody were purchased from Abcam Inc. The antibody was dilution at 1:1,000.

\section{Animals}

$\mathrm{BALB} / \mathrm{c}$ male nude mice, 6-8 weeks old, weighing 20-25 g, were obtained from Vital River Laboratories, China. All the animals were housed in an environment with temperature of $22^{\circ} \mathrm{C} \pm 1{ }^{\circ} \mathrm{C}$, relative humidity of $50 \% \pm 1 \%$ and a light/dark cycle of 12/12 hours. All animal studies (including the mice euthanasia procedure) were performed in compliance with the Accreditation of Laboratory Animal Care International (AAALAC) and Institutional Animal Care and Use Committee (IACUC) of Chongqing Medical University guidelines and approved by the IACUC of Chongqing Medical University. Mice were randomly divided in two groups: LV3shCAV2-1 group $(n=10)$ and LV3-NC group $(n=10)$. Human RCC cells OS-RC-2 were infected with LV3-shCAV2-1 or LV3-NC and injected $\left(5 \times 10^{6}\right.$ cells per mouse in $\left.200 \mu \mathrm{L}\right)$ subcutaneously into the left armpit of nude mice. Then, 21 days later, animals were sacrificed under isoflurane anesthesia.

\section{Statistical evaluation}

All values were expressed as mean \pm SEM. Statistical analysis was performed by Student's $t$-test. A $P$-value of $<0.05$ was considered statistically significant. 


\section{Results}

\section{CAV2 expression was increased in RCC tissue}

The ONCOMINE database was used to investigate differential genes expression. ${ }^{25-27}$ In this research, three independent studies from the ONCOMINE database were conducted to analyze the expression of CAV2 in RCC and normal kidney tissues. Three independent studies (Higgins Renal, Gumz
Renal and Jones Renal) showed that the expression of CAV2 was higher in RCC compared to normal kidney tissues (fold changes were 5.716, 5.312, 8.918, 8.432, 2.618 and 4.156, respectively) $(P=4.27 \mathrm{E}-12,8.61 \mathrm{E}-19,3.75 \mathrm{E}-4,9.06 \mathrm{E}-4$, 0.005 and 0.002 , respectively) (Figure 1A-F).

Furthermore, the evaluation of the CAV2 expression with OS was performed using the Human Protein Atlas online tool. Briefly, we found a significant correlation between high
A

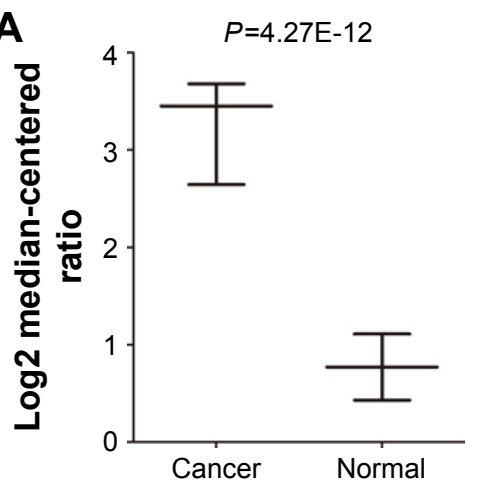

D

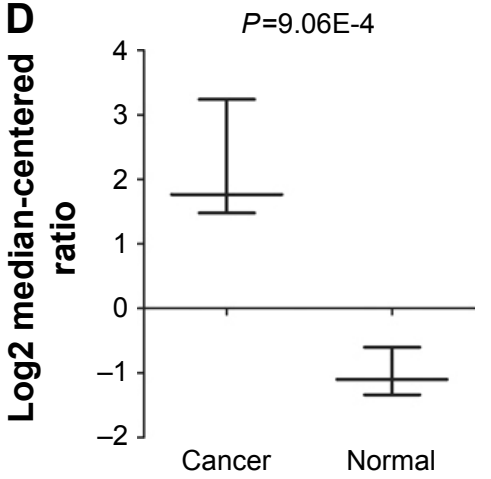

B
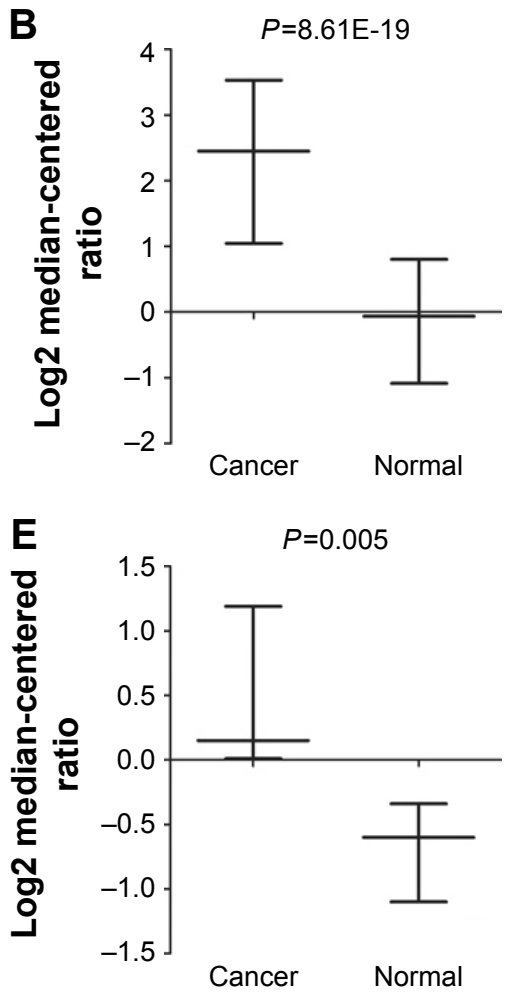

G
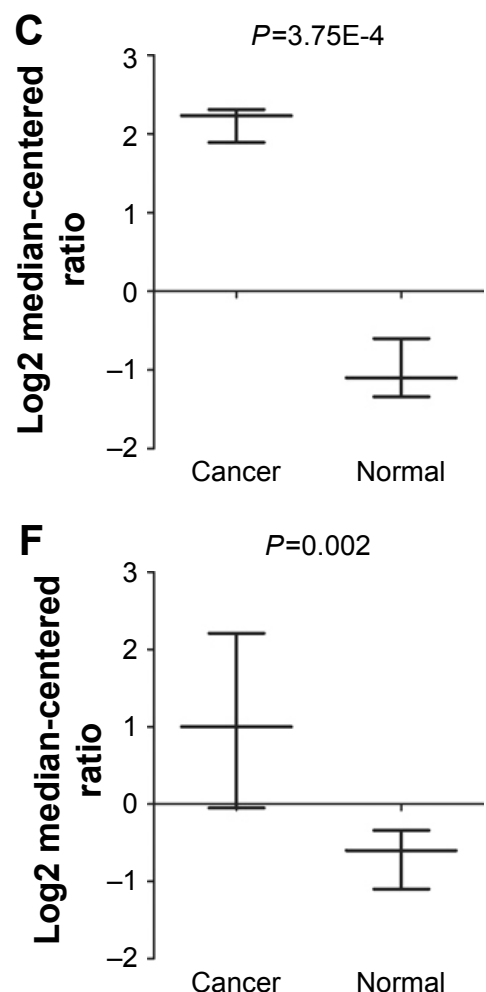

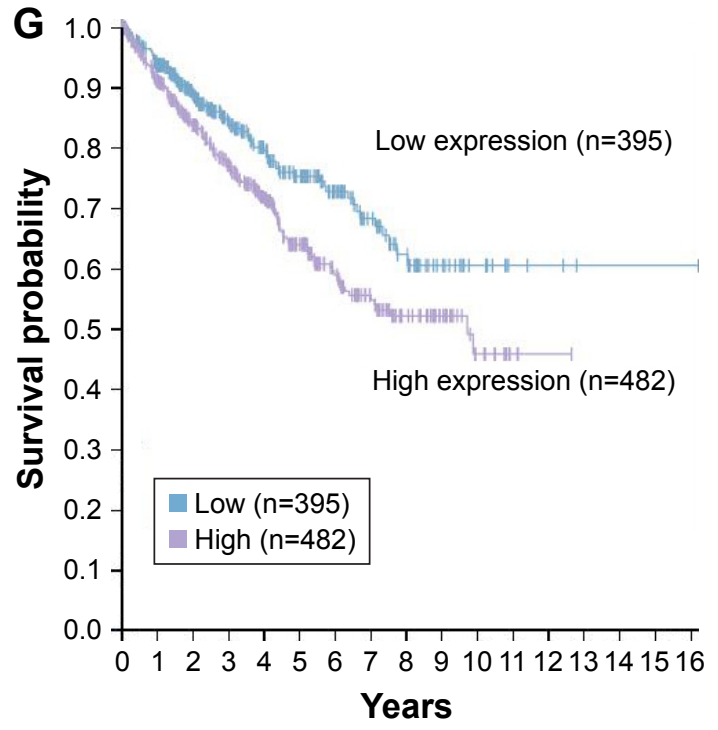

Figure I CAV2 expression was elevated and associated with poor outcome in renal cell carcinoma.

Notes: The mRNA expression of CAV2 in renal cell carcinoma was analyzed. Data derived from the ONCOMINE database. The mRNA expression of CAV2 in renal cell cancer was increased compared to normal renal tissues (A-F). Evaluation of the CAV2 genes with OS was performed using the Online Tool (https://www.proteinatlas.org/; G). Abbreviations: CAV2, Caveolin-2; OS, overall survival. 

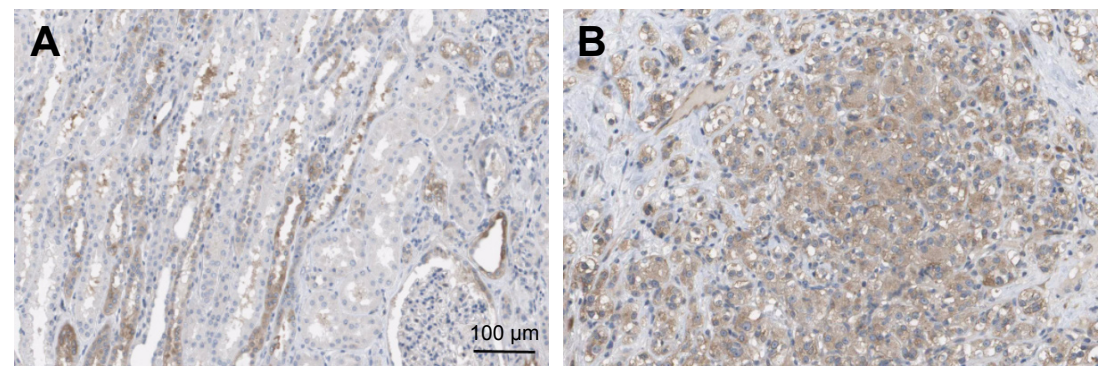

Figure 2 CAV2 expression was detected by immunohistochemistry (IHC)

Notes: CAV2 was located in cytoplasmic and membranous (A). The expression of CAV2 in renal cell cancer tissues (B) was increased compared to the normal renal tissues (A). $200 \times$ original.

Abbreviation: CAV2, Caveolin-2.

CAV2 and poor overall survival (OS) in patients with invasive RCC ( $P=3.44 \mathrm{e}-3$; Figure 1G).

\section{The increased expression of CAV2 was associated with cancer progression}

Next, we investigated the location and expression of CAV2 in RCC tissues and found that CAV2 was primary localized on the plasma membrane and cytoplasm (Figure 2A). In addition, the CAV2 expression was high staining in kidney carcinoma (Figure 2B). CAV2 in tubules cells was medium staining. However, CAV2 was not detected in glomeruli cells (Figure 2A). Furthermore, the CAV2 expression was correlated to tumor stage, and its expression was significantly higher in advanced stage (stage III/IV) compared to early stage tumor (stage I/II) $(P<0.05$; Table 1). Moreover, the expression of CAV2 significantly correlated with the tumor grade (grades $2-3$ vs $1, P<0.05$; Table 1 ). However, the associations between CAV2 expression and age were not significant $(P>0.05$; Table 1$)$.

\section{Silencing of CAV2 inhibited proliferation, migration and invasion of OS-RC-2}

The expression of CAV2 was reduced in LV3-shCAV2-1 and LV3-shCAV2-2 infected OS-RC-2 cells compared with LV3-NC infected OS-RC-2 cells (Figure 3A). The cell proliferation, migration and invasion of OS-RC-2 cells infected with LV3-shCAV2-1 and LV3-shCAV2-2 decreased compared to cells infected with LV3-NC $(P<0.05$; Figure 3B-F).

\section{CAV2 regulated EGFR/PI3K/Akt pathway}

The EGFR/PI3K/Akt pathway has an important role in RCC. We further investigated the correlation between CAV2 and EGFR, PI3K and Akt using an online tool (http://gepia. cancer-pku.cn/detail.php). Our results showed that the expression of CAV2 in RCC was positively correlated with EGFR, PI3K and Akt (Figure 4A-C). In addition, we found that silencing of CAV2 reduces the expression of EGFR, PI3K and p-Akt in OS-RC-2 (Figure 4D and E).

Table I Association of CAV2 expression with clinicopathological characteristics in 86 patients of kidney cancer

\begin{tabular}{|c|c|c|c|c|}
\hline \multirow[t]{2}{*}{ Characteristics } & \multirow[t]{2}{*}{ No of patients $(n=96)$} & \multicolumn{2}{|l|}{ CAV2 expression } & \multirow[t]{2}{*}{$P$-value } \\
\hline & & Low no (\%) & High no (\%) & \\
\hline Age (years) & & & & $>0.05$ \\
\hline$<50$ & 36 & $19(52.78 \%)$ & $17(47.22 \%)$ & \\
\hline$\geq 50$ & 60 & $34(56.67 \%)$ & $26(43.33 \%)$ & \\
\hline Normal tissues & 10 & $10(100 \%)$ & $0(0 \%)$ & $<0.05$ \\
\hline Cancer tissues & 86 & $43(50.00 \%)$ & $43(50.00 \%)$ & \\
\hline \multicolumn{5}{|l|}{ FIGO stage } \\
\hline $1 / I I$ & 70 & $4 \mathrm{I}(58.57 \%)$ & $29(41.12 \%)$ & $<0.05$ \\
\hline III/IV & 16 & $2(12.50 \%)$ & $14(87.50 \%)$ & \\
\hline \multicolumn{5}{|l|}{ Grade } \\
\hline 1 & 56 & 37 (66.07\%) & $19(33.93 \%)$ & \\
\hline 2 & 22 & $5(22.73 \%)$ & $17(77.27 \%)$ & \\
\hline \multirow[t]{2}{*}{3} & 8 & $\mathrm{I}(12.50 \%)$ & 7 (87.50\%) & \\
\hline & & Grade $2-3$ versus I & & $<0.05$ \\
\hline
\end{tabular}

Abbreviations: CAV2, Caveolin-2; FIGO, International Federation of Gynecology and Obstetrics. 
A

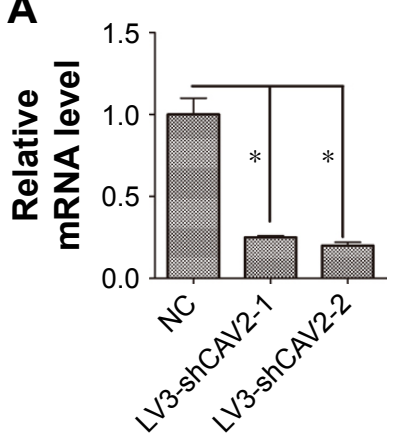

B

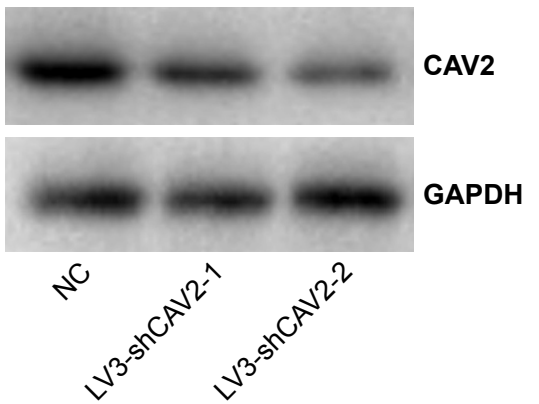

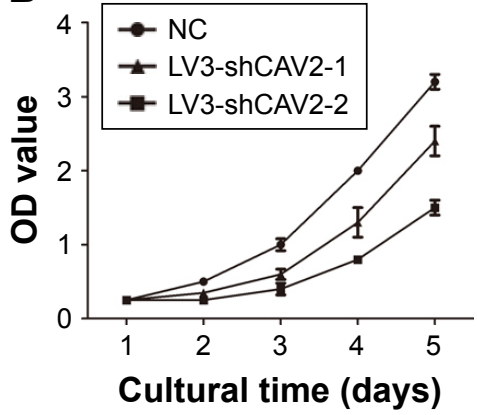

C
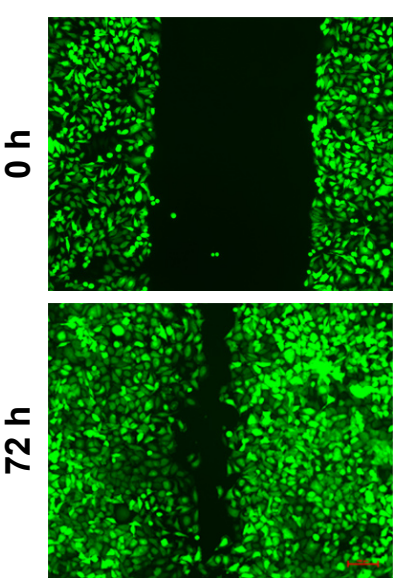

E

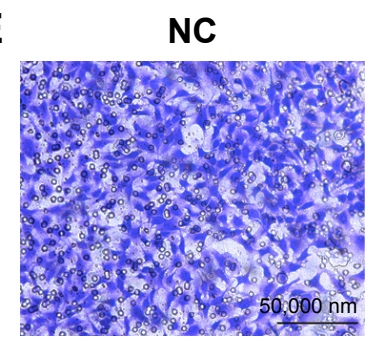

LV3-shCAV2-1
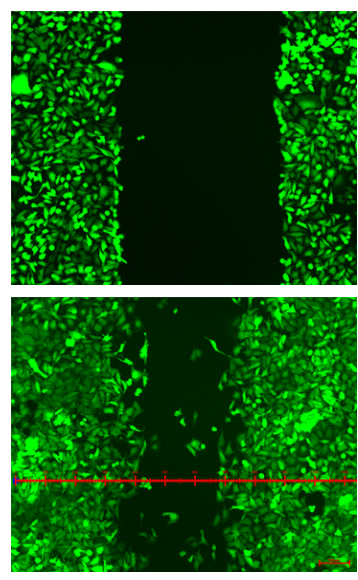

LV3-shCAV2-1

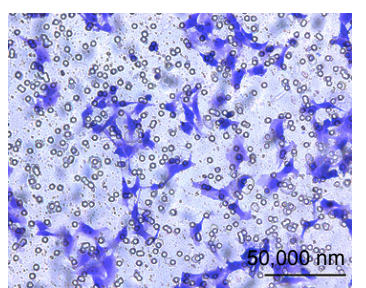

LV3-shCAV2-2
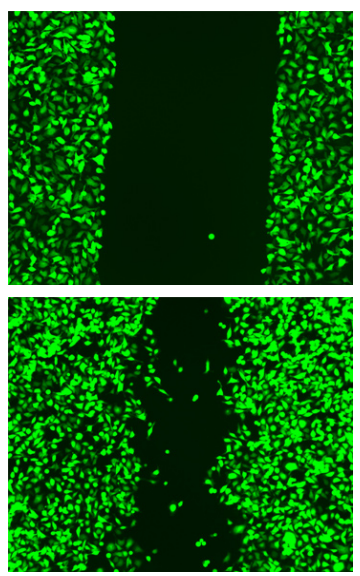

LV3-shCAV2-2

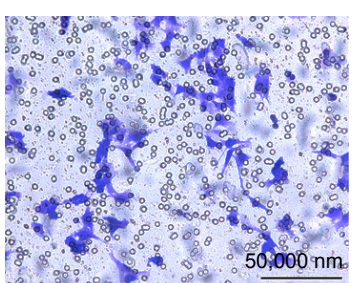

D
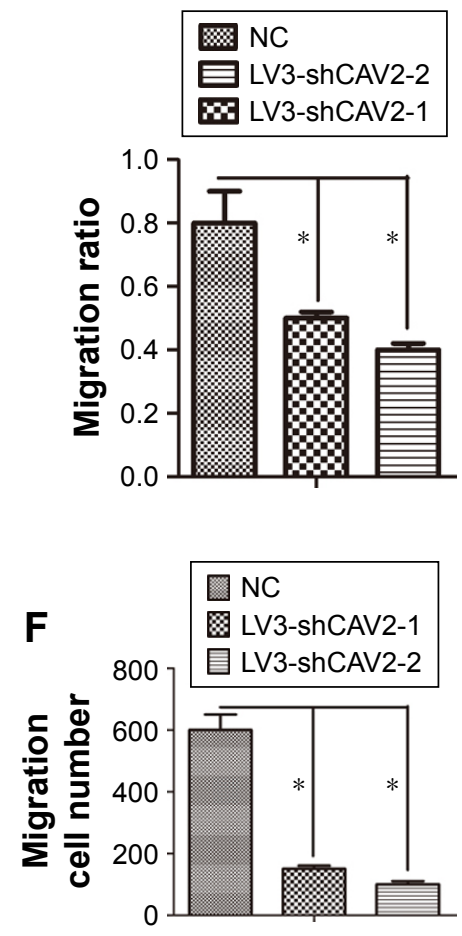

Figure 3 CAV2 regulates cellular proliferation, migration and invasion.

Notes: (A) CAV2 mRNA and protein level were downregulated by infected with LV3-shCAV2-I or LV3-shCAV2-2. (B) Renal cell cancer OS-RC-2 cells were infected with LV3-NC, LV3-shCAV2-I or LV3-shCAV2-2. Cell proliferation was assessed by CCK-8. (C, D) Renal cell cancer OS-RC-2 cells migration ability was detected by the wound healing assay. The migration of LV3-shCAV2-I or LV3-shCAV2-2 infected OS-RC-2 cells was lower as compared with LV3-NC infected cells. (E, F) Renal cell cancer OS-RC-2 cells invasion ability was detected by Matrigel invasion assays. The invasion ability of LV3-shCAV2-I or LV3-shCAV2-2 infected OS-RC-2 cells was decreased compared with LV3-NC infected cells. Original magnification, 200x original. Error bars represent standard error. $* P<0.05$.

Abbreviation: CAV2, Caveolin-2.

\section{Silencing CAV2 inhibited the growth of OS-RC-2 cells in vivo}

To investigate the role of CAV2 in vivo, OS-RC-2 cells infected with LV3-NC and LV3-shCAV2-1 were injected in nude mice. Briefly, the average tumor volume and weight were decreased in LV3-shCAV2-1 group compared to LV3-NC group $(P<0.05)$ (Figure $5 \mathrm{~A}-\mathrm{C})$. In addition, lower expression of EGFR, PI3K and p-Akt were found in tumors derived from LV3-shCAV2-1 compared to that in the LV3-NC group (Figure 5D).

\section{Discussion}

In this study, we found that CAV2 was abnormally expressed in RCC. The expression of CAV2 was related to the stage and grade of RCC, while high expression of CAV2 suggested a poor prognosis. We also found that CAV2 regulated the EGFR/PI3K/Akt signaling pathway.

Previous studies have found that CAV2 is associated with the occurrence and development of tumors. The expression of CAV2 has been observed in $5.9 \%$ of all breast cancer, while CAV2 expression has been reported as being strongly 


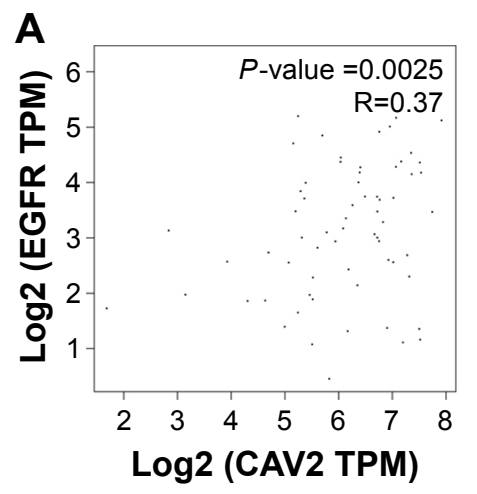

D

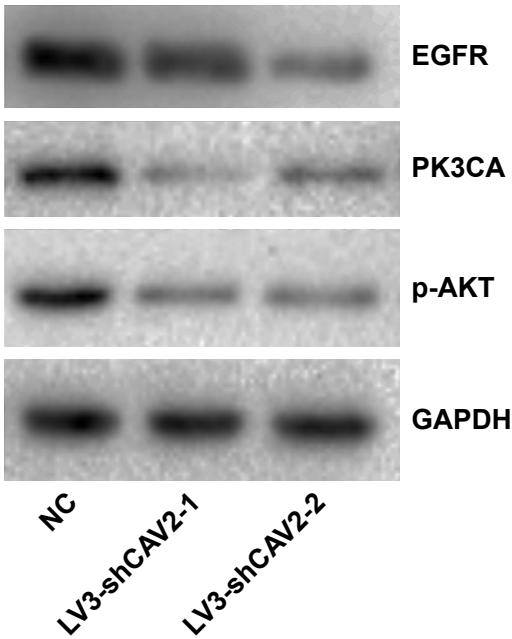

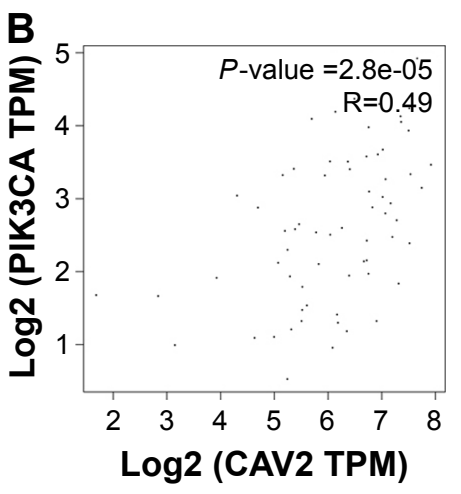

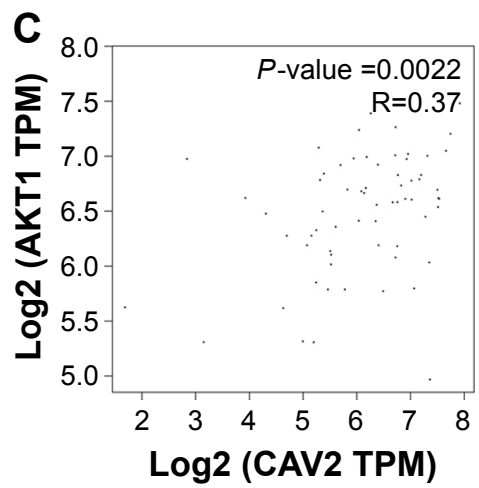

Figure 4 CAV2 regulates the EGFR/PI3K/Akt signaling pathway.

Notes: (A-C) The correlation between CAV2 and EGFR/PI3K/AKT were analyzed using the Online Tool (http://gepia.cancer-pku.cn/). (D) Silencing CAV2 inhibited the expression of EGFR, PI3K and $\mathrm{p}-\mathrm{AKT}$. (E) The relative protein expression. Error bars represent standard error. $* P<0.05 ; * * P<0.001$.

Abbreviations: CAV2, Caveolin-2; EGFR, epidermal growth factor receptor; PI3K, phosphatidylinositol 3-kinase; Akt, protein kinase B.

associated with high histological grade. ${ }^{13}$ CAV2 is mainly expressed in breast cancers and is associated with poor prognosis. ${ }^{14}$ However, another study found that CAV2 expression is suppressed in breast cancer tissues compared to normal tissues, and that the reduced CAV1 is significantly associated with increasing tumor size. ${ }^{15}$ Another study has suggested that there is a correlation between plasma CAV2 levels and progression of prostate cancer. ${ }^{16} \mathrm{CAV} 2$ can promote tumor growth by supporting tumor-induced angiogenesis. Because of this function of CAV2 in tumor microenvironment, CAV2 is regarded as a potentially novel target for lung cancer therapy. ${ }^{28}$ In esophageal squamous cell carcinoma, the increased expression of CAV2 correlates with a tumor progression and poor prognosis. So, CAV2, which has been shown to correlate with $\mathrm{RCC},{ }^{17}$ is a potential biomarker for diagnosis of esophageal squamous cell carcinoma. ${ }^{29}$ However, the expression and function of CAV2 is not known in RCC. Our results revealed that CAV2 had increased expression in RCC. The increased expression of CAV2 was associated with cancer progression.
CAV2 high expression was significantly correlated with poor OS in all patients with invasive RCC. Silencing of CAV2 caused reduction in cell proliferation and growth with retarded entry into the $\mathrm{S}$ phase. ${ }^{30}$ Our data revealed that silencing CAV2 inhibited the cellular proliferation, migration and invasion in RCC. Our results furthermore indicated that high expression of CAV2 promoted the progression of RCC.

The expression of EGFR correlates with prognosis in patients with clear cell RCC. ${ }^{31}$ Suppression of the EGFR signaling pathway retards RCC progression. ${ }^{32}$ The PI3K/ AKT pathway is highly activated in RCC progression. This pathway is a promising drug target. ${ }^{33-37}$ In this research, we found that silencing CAV2 inhibited the expression of EGFR, PI3K and p-AKT in vitro and in vivo. We also found that the expression of CAV2 was positively correlated with EGFR, PI3K and AKT. Therefore, CAV2 may promote the malignant behavior through the EGFR/PI3K/AKT pathway in RCC. Inhibition of this pathway could serve as a promising target in RCC. 
A
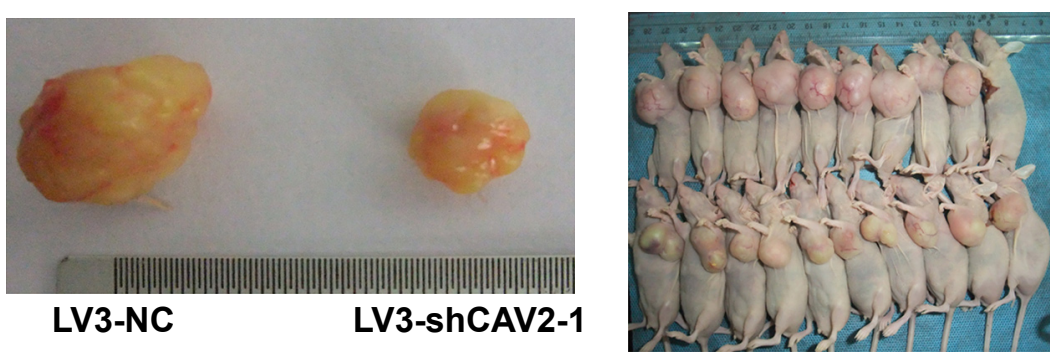

LV3-NC

LV3-NC

LV3-shCAV2-1

B
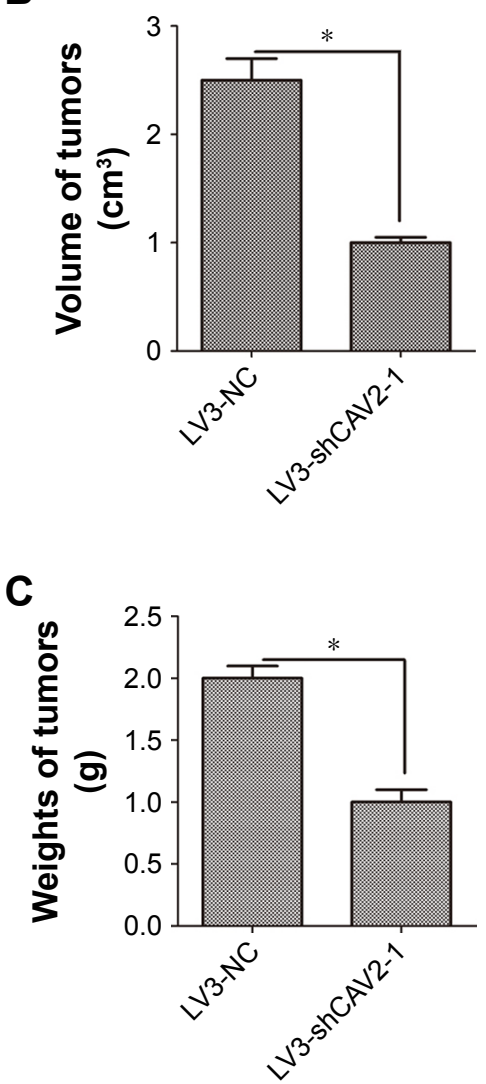

D
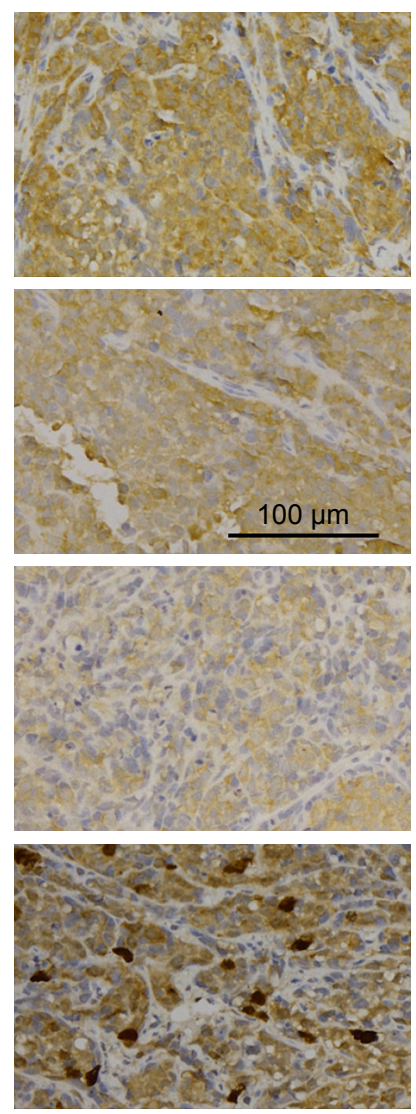

LV3-NC

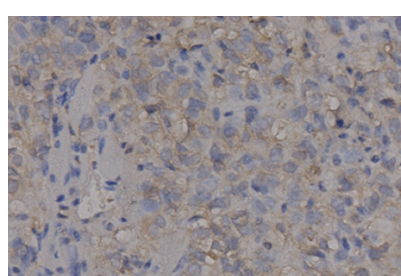

CAV2

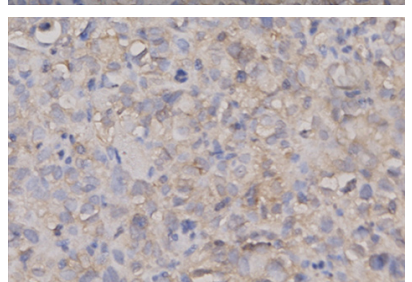

EGFR

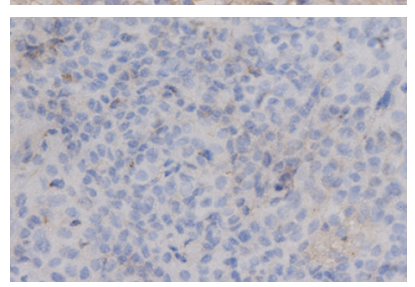

PI3K

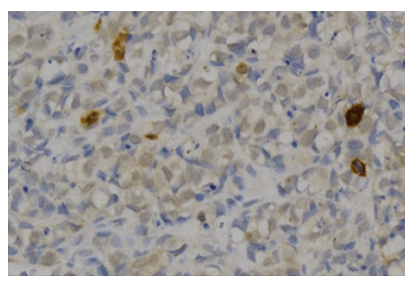

LV3-shCAV2-1

Figure 5 CAV2 regulated tumorigenesis in nude mice model.

Notes: (A-C) Mean tumor volume and weight on day 28 after tumor cell injection. LV3-shCAV2-I or LV3-NC infected OS-RC-2 cells were implanted s.c. into the left armpit. (D) Immunohistochemical analysis of CAV2, EGFR, PI3K and p-AKT expression were performed on tumor xenografts. Representative images are shown (original magnification $\times 200$ ). $* P<0.05$.

Abbreviations: CAV2, Caveolin-2; EGFR, epidermal growth factor receptor; PI3K, phosphatidylinositol 3-kinase; Akt, protein kinase B.

To sum up, our findings indicated that CAV2 played a role in promoting the growth of RCC. Inhibition of the EGFR/ $\mathrm{PI} 3 \mathrm{~K} / \mathrm{AKT}$ signaling pathway could be used as a potential approach for the treatment of RCC.

\section{Disclosure}

The authors report no conflicts of interest in this work.

\section{References}

1. Weiss RH. Metabolomics and metabolic reprogramming in kidney cancer. Semin Nephrol. 2018;38(2):175-182.
2. Pendón-Ruiz de Mier MV, Agüera ML, Navarro MD, Rodriguez-Benot A, Aljama P. Prevalence and survival of cancer after pancreas-kidney transplantation. Transplant Proc. 2018;50(2):669-672.

3. Ge Y, Weygant N, Qu D, et al. Alternative splice variants of DCLK1 mark cancer stem cells, promote self-renewal and drug-resistance, and can be targeted to inhibit tumorigenesis in kidney cancer. Int $J$ Cancer. Epub 2018 March 25.

4. Chang WH, Horng HC, Yeh CC, et al. Risks of female genital tract related cancers (gynecological cancers) or breast cancer in women with and without chronic kidney disease: a population-based cohort study in Taiwan. Medicine. 2018;97(12):e0157.

5. Soria F, Beleni AI, D'Andrea D, et al. Pseudoprogression and hyperprogression during immune checkpoint inhibitor therapy for urothelial and kidney cancer. World J Urol. Epub 2018 March 16. 
6. Kelsey R. Kidney cancer: ccrcc1-4 classification for prediction of relapse. Nat Rev Urol. 2018;15(4):205.

7. Torres da Costa E, Silva V, Costalonga EC, Coelho FO, Caires RA, Burdmann EA. Assessment of kidney function in patients with cancer. Adv Chronic Kidney Dis. 2018;25(1):49-56.

8. Hnasko R, Lisanti MP. The biology of caveolae: lessons from caveolin knockout mice and implications for human disease. Mol Interv. 2003;3(8):445-464.

9. Fu SJ, Jeng CJ, Ma CH, et al. Ubiquitin ligase RNF138 promotes episodic Ataxia Type 2-associated aberrant degradation of human $\mathrm{Ca}_{\mathrm{v}} 2.1$ (P/Q-Type) calcium channels. J Neurosci. 2017;37(9):2485-2503.

10. Zhou X, Wang W, Zhang S, et al. CACNA1B $\left(\mathrm{Ca}_{\mathrm{v}} 2.2\right)$ overexpression and its association with clinicopathologic characteristics and unfavorable prognosis in non-small cell lung cancer. Dis Markers. 2017; 2017:6136401-61364018.

11. Tsou WL, Soong BW, Paulson HL, Rodríguez-Lebrón E. Splice isoform-specific suppression of the Cav2.1 variant underlying spinocerebellar ataxia type 6. Neurobiol Dis. 2011;43(3):533-542.

12. Harkins AB, Cahill AL, Powers JF, Tischler AS, Fox AP. Deletion of the synaptic protein interaction site of the N-type (CaV2.2) calcium channel inhibits secretion in mouse pheochromocytoma cells. Proc Natl Acad Sci U S A. 2004;101(42):15219-15224.

13. Elsheikh SE, Green AR, Rakha EA, et al. Caveolin 1 and Caveolin 2 are associated with breast cancer basal-like and triple-negative immunophenotype. Br J Cancer. 2008;99(2):327-334.

14. Savage K, Leung S, Todd SK, et al. Distribution and significance of caveolin 2 expression in normal breast and invasive breast cancer: an immunofluorescence and immunohistochemical analysis. Breast Cancer Res Treat. 2008;110(2):245-256.

15. Sagara Y, Mimori K, Yoshinaga K, et al. Clinical significance of Caveolin-1, Caveolin-2 and HER2/neu mRNA expression in human breast cancer. Br J Cancer. 2004;91(5):959-965.

16. Sugie S, Mukai S, Yamasaki K, Kamibeppu T, Tsukino H, Kamoto T. Significant association of Caveolin-1 and Caveolin-2 with prostate cancer progression. Cancer Genomics Proteom. 2015;12(6):391-396.

17. Liu X, Wang J, Sun G. Identification of key genes and pathways in renal cell carcinoma through expression profiling data. Kidney Blood Press Res. 2015;40(3):288-297.

18. Zhang X, Zhang Y, Miao Y, Zhou H, Jiang G, Wang E. TMEM17 depresses invasion and metastasis in lung cancer cells via ERK signaling pathway. Oncotarget. 2017;8(41):70685-70694.

19. Meng F, Liu H, Liu S, Ma R. The clinical significance of HPIP and the associated prognosis in cervical cancer. Oncotarget. 2017;8(41): 70262-70270.

20. $\mathrm{Xu} \mathrm{H}, \mathrm{Fu} \mathrm{S}$, Chen Q, et al. The function of oxytocin: a potential biomarker for prostate cancer diagnosis and promoter of prostate cancer. Oncotarget. 2017;8(19):31215-31226.

21. Jingsong H, Hong G, Yang J, et al. siRNA-mediated suppression of collagen type iv alpha 2 (COL4A2) mRNA inhibits triple-negative breast cancer cell proliferation and migration. Oncotarget. 2017;8(2):2585-2593.

22. Wu H, Bi J, Peng Y, et al. Nuclear receptor NR4A1 is a tumor suppressor down-regulated in triple-negative breast cancer. Oncotarget. 2017;8(33): 54364-54377.
23. Xue MQ, Liu J, Sang JF, Su L, Yao YZ. Expression characteristic of CXCR1 in different breast tissues and the relevance between its expression and efficacy of neo-adjuvant chemotherapy in breast cancer. Oncotarget. 2017;8(30):48930-48937.

24. Li Y, Jin L, Ye F, et al. Isoform expression patterns of EPHA10 protein mediate breast cancer progression by regulating the E-cadherin and $\beta$-catenin complex. Oncotarget. 2017;8(18):30344-30356.

25. Lee A, Lee SH, Jung CK, et al. Use of the Ion AmpliSeq Cancer Hotspot Panel in clinical molecular pathology laboratories for analysis of solid tumours: with emphasis on validation with relevant single molecular pathology tests and the Oncomine Focus Assay. Pathol Res Pract. 2018; 214(5):713-719.

26. Ye L, Li H, Zhang F, Lv T, Liu H, Song Y. Expression of KIF23 and its prognostic role in non-small cell lung cancer: analysis based on the datamining of oncomine. Zhongguo Fei Ai Za Zhi. 2017;20(12):822-826.

27. Xu B, Liu N, Chen SQ, et al. Expression of SRD5A1 and its prognostic role in prostate cancer: analysis based on the data-mining of ONCOMINE. Zhonghua Nan Ke Xue. 2016;22(9):771-776.

28. Liu Y, Jang S, Xie L, Sowa G. Host deficiency in caveolin-2 inhibits lung carcinoma tumor growth by impairing tumor angiogenesis. Cancer Res. 2014;74(22):6452-6462.

29. Ando T, Ishiguro H, Kimura M, et al. The overexpression of caveolin-1 and caveolin-2 correlates with a poor prognosis and tumor progression in esophageal squamous cell carcinoma. Oncol Rep. 2007;18(3): 601-609.

30. Lee S, Kwon H, Jeong K, Pak Y. Regulation of cancer cell proliferation by caveolin-2 down-regulation and re-expression. Int J Oncol. 2011;38(5):1395-1402.

31. Dorđević G, Matušan Ilijaš K, Hadžisejdić I, Maričić A, Grahovac B, Jonjić N. EGFR protein overexpression correlates with chromosome 7 polysomy and poor prognostic parameters in clear cell renal cell carcinoma. J Biomed Sci. 2012;19:40.

32. Liang L, Li L, Zeng J, et al. Inhibitory effect of silibinin on EGFR signal-induced renal cell carcinoma progression via suppression of the EGFR/MMP-9 signaling pathway. Oncol Rep. 2012;28(3):999-1005.

33. di J, Gao K, Qu D, Yang J, Zheng J. Rap2B promotes angiogenesis via $\mathrm{PI} 3 \mathrm{~K} / \mathrm{AKT} / \mathrm{VEGF}$ signaling pathway in human renal cell carcinoma. Tumour Biol. 2017;39(7):1010428317701653.

34. Zhao Z, Liu H, Hou J, et al. Tumor protein D52 (TPD52) inhibits growth and metastasis in renal cell carcinoma cells through the PI3K/ Akt signaling pathway. Oncol Res. 2017;25(5):773-779.

35. Zhang H, Sheng L, Tao J, et al. Depletion of the triggering receptor expressed on myeloid cells 2 inhibits progression of renal cell carcinoma via regulating related protein expression and PTEN-PI3K/Akt pathway. Int J Oncol. 2016;49(6):2498-2506.

36. Guo H, German P, Bai S, et al. The PI3K/AKT pathway and renal cell carcinoma. J Genet Genomics. 2015;42(7):343-353.

37. Sun Z, Cao B, Wu J. Protease-activated receptor 2 enhances renal cell carcinoma cell invasion and migration via PI3K/AKT signaling pathway. Exp Mol Pathol. 2015;98(3):382-389.
OncoTargets and Therapy

\section{Publish your work in this journal}

OncoTargets and Therapy is an international, peer-reviewed, open access journal focusing on the pathological basis of all cancers, potential targets for therapy and treatment protocols employed to improve the management of cancer patients. The journal also focuses on the impact of management programs and new therapeutic agents and protocols on
Dovepress

patient perspectives such as quality of life, adherence and satisfaction The manuscript management system is completely online and includes a very quick and fair peer-review system, which is all easy to use. Visit http://www.dovepress.com/testimonials.php to read real quotes from published authors. 